\title{
Avaliação de estresse, ansiedade e fatores associados entre alunos do Programa Institucional de Bolsas de Iniciação Científica - Ensino Médio
}

\author{
Rebeca B. Waisman*, Brunna V. C. Gondinho, Jaqueline V. Bulgareli, Karine L. Cortellazzi, Luciane M. \\ Guerra.
}

\section{Resumo}

O presente estudo avaliou o estresse, a ansiedade e fatores socioeconômicos e demográficos a eles associados entre alunos participantes do Programa Institucional de Bolsas de Iniciação Científica - Ensino Médio (PIBIC -EM) atuantes na Faculdade de Odontologia de Piracicaba (FOP-UNICAMP). Os participantes responderam instrumentos de pesquisa validados, que investigaram as variáveis relacionadas a este estudo, incluindo as variáveis dependentes (ansiedade e stress) medidas, respectivamente, pelo BAI e ISS, e as variáveis independentes (socioeconômicas e demográficas). Foi realizado Odds Ratio e a análise bivariada pelo teste qui-quadrado ou exato de Fisher, no nível de significância de $5 \%$, para testar a associação entre a variável dependente e variáveis independentes. Quem apresentou estresse na fase exaustão tem mais chances $(\mathrm{OR}=13,33)$ de ter ansiedade moderada/grave.

\section{Palavras-chave: \\ Ansiedade. Estresse Psicológico. Ensino fundamental e médio.}

\section{Introdução}

O Programa Institucional De Bolsas De Iniciação Científica Ensino Médio (PIBIC-EM) é uma Iniciativa que visa despertar vocação científica e incentivar talentos potenciais entre estudantes do ensino fundamental, médio e profissional da rede pública, mediante sua participação em atividades de pesquisa científica ou tecnológica, orientadas por pesquisador qualificado, em instituições de ensino superior ou institutos/centros de pesquisas (Conselho Nacional de Desenvolvimento Científico e Tecnológico, 2017).

Tanto o estresse quanto a ansiedade são emoções que apresentam como resposta fisiológica a ação do sistema nervoso simpático. Mantidas estas respostas, pode haver uma evolução física para a fase patológica de exaustão na qual o organismo não sendo capaz de cessar a ação do estressor, torna-se suscetível a doenças. Mediante tais circunstâncias, pode-se notar como alguns dos reflexos na vida do indivíduo: fadiga, alcoolismo, uso de drogas, baixo rendimento no trabalho, bem como, falta de interesse/motivação na realização de outras atividades (Silva e Marchi,1997).

Nesse sentido, o contato com a vida acadêmica, o estímulo à postura crítica e o conhecimento de novos caminhos profissionais são essenciais na formação do adolescente e no seu amadurecimento, o que corrobora a importância do PIBIC EM. Entretanto, identificar os estados de ansiedade e estresse nesses adolescentes parece ser fundamental no sentido de fornecer informações para o aprimoramento das ações do referido programa e, assim, perseguir sua otimização na formação crítica de adolescents. Assim, o objetivo deste estudo foi avaliar o estresse, ansiedade e fatores socioeconômicos e demográficos a eles associados entre alunos de iniciação científica júnior.

\section{Resultados e Discussão}

Os participantes responderam instrumentos de pesquisa validados, que investigaram as variáveis relacionadas a este estudo, incluindo as variáveis dependentes (ansiedade e stress) medidas, respectivamente, pelo BAI e ISS, e as variáveis independentes (socioeconômicas e demográficas).

Os resultados são expostos a seguir, a saber:
Tabela 1: Associação da ansiedade ao estresse e às variáveis sociodemográficas

\begin{tabular}{|c|c|c|c|c|c|c|c|}
\hline \multirow{2}{*}{ Variáveis } & \multirow{2}{*}{$\begin{array}{c}\text { Categoria } \\
\text { s }\end{array}$} & \multirow{2}{*}{$\begin{array}{c}\text { Amostra } \\
\begin{array}{c}n=43 \\
(100 \%)\end{array}\end{array}$} & \multicolumn{2}{|c|}{ ANSIFDADE } & \multirow{2}{*}{ OR } & \multirow[b]{2}{*}{ IC } & \multirow[b]{2}{*}{ p-valor } \\
\hline & & & Leve e mínimo & Moderado e grave & & & \\
\hline \multirow{2}{*}{ Renda } & $\begin{array}{l}\text { Até R\$ } \\
3255,00\end{array}$ & $20(46,51 \%)$ & $11(55 \%)$ & $9(45 \%)$ & 1,87 & $0,53-6,53$ & 0,5033 \\
\hline & $\begin{array}{l}\text { Acima de } \\
3255,00\end{array}$ & $23(53,49 \%)$ & $16(69,56 \%)$ & $7(30,44 \%)$ & ref & & \\
\hline \multirow{2}{*}{$\begin{array}{l}\text { Pessoas } \\
\text { na casa }\end{array}$} & $\begin{array}{c}\text { Até } 4 \\
\text { pessoas }\end{array}$ & $13(30,23 \%)$ & $5(38,46 \%)$ & $8(61,54 \%)$ & 4,40 & $1,11-17,48$ & 0,0674 \\
\hline & $\begin{array}{c}\text { Acima de } 4 \\
\text { pessoas }\end{array}$ & $30(69,77 \%)$ & $22(73,33 \%)$ & $8(26,67 \%)$ & ref & & \\
\hline \multirow{2}{*}{$\begin{array}{l}\text { Escolarida } \\
\text { de do pai }\end{array}$} & $\begin{array}{c}\text { Até } 2^{\circ} \\
\text { Grau } \\
\text { Completo }\end{array}$ & $12(27,91 \%)$ & $6(50 \%)$ & $6(50 \%)$ & 0,20 & $0,03-1,33$ & 0,1939 \\
\hline & $\begin{array}{c}\text { Acima do } \\
2^{\circ} \text { Grau } \\
\text { Completo } \\
\end{array}$ & $31(72,09 \%)$ & $21(67,74 \%)$ & $10(32,26 \%)$ & ref & & \\
\hline \multirow{2}{*}{$\begin{array}{l}\text { Escolarida } \\
\text { de da mãe }\end{array}$} & $\begin{array}{c}\text { Até } 2^{\circ} \\
\text { Grau } \\
\text { Completo }\end{array}$ & $16(37,21 \%)$ & $8(50 \%)$ & $8(50 \%)$ & 2,37 & $0,66-8,56$ & 0,3128 \\
\hline & $\begin{array}{c}\text { Acima do } \\
2^{\circ} \text { Grau } \\
\text { Completo } \\
\end{array}$ & $27(62,79 \%)$ & $19(70,37 \%)$ & $8(29,63 \%)$ & ref & & \\
\hline \multirow{2}{*}{$\begin{array}{l}\text { Tipo de } \\
\text { moradia }\end{array}$} & $\begin{array}{l}\text { Residência } \\
\text { própria }\end{array}$ & $23(53,49 \%)$ & $14(60,87 \%)$ & $9(39,13 \%)$ & 1,19 & $0,34-4,12$ & 0,9707 \\
\hline & $\begin{array}{c}\text { Residência } \\
\text { nāo } \\
\text { própria } \\
\end{array}$ & $20(46,51 \%)$ & $13(65 \%)$ & $7(35 \%)$ & ref & & \\
\hline \multirow{2}{*}{$\begin{array}{c}\text { Automóve } \\
1\end{array}$} & $\begin{array}{c}\text { Até 1 } \\
\text { automóvel }\end{array}$ & $14(32,56 \%)$ & $10(71,43 \%)$ & $4(28,57 \%)$ & 0,57 & $0,14-2,24$ & 0,6330 \\
\hline & $\begin{array}{c}\text { Possui } \\
\text { mais de 1 } \\
\text { automóvel } \\
\end{array}$ & $29(67,44 \%)$ & $17(58,62 \%)$ & $12(41,38 \%)$ & ref & & \\
\hline \multirow{2}{*}{$\begin{array}{l}\text { Estresse } \\
\text { F1 }\end{array}$} & $\begin{array}{l}\text { Não } \\
\text { Alerta }\end{array}$ & $39(90,70 \%)$ & $25(64,10 \%)$ & $14(35,90 \%)$ & 0,56 & $0,07-4,42$ & 0,9899 \\
\hline & Alerta & $4(9,30 \%)$ & $2(50 \%)$ & $2(50 \%)$ & ref & & \\
\hline \multirow{2}{*}{$\begin{array}{l}\text { Estresse } \\
\text { F2 }\end{array}$} & $\begin{array}{l}\text { Não } \\
\text { resistência }\end{array}$ & $17(39,53 \%)$ & $14(82,35 \%)$ & $3(17,65 \%)$ & 0,21 & $0,05-0,93$ & 0,0683 \\
\hline & $\begin{array}{c}\text { Resistênci } \\
\text { a }\end{array}$ & $26(60,47 \%)$ & $13(50 \%)$ & $13(50 \%)$ & ref & & \\
\hline \multirow{2}{*}{$\begin{array}{l}\text { Estresse } \\
\text { F3 }\end{array}$} & \begin{tabular}{c|} 
Não \\
exaustão
\end{tabular} & $30(69,77 \%)$ & $24(80 \%)$ & $6(20 \%)$ & ref & $2,77-64,09$ & 0,0014 \\
\hline & Exaustão & $13(30,23 \%)$ & $3(23,08 \%)$ & $10(76,92 \%)$ & 13,33 & & \\
\hline
\end{tabular}

\section{Conclusões}

Quem apresentou estresse na fase exaustão tem mais chances $(\mathrm{OR}=13,33)$ de ter ansiedade moderada/grave.

\section{Agradecimentos}

Nossos agradecimentos ao CNPq.

Conselho Nacional de Desenvolvimento Científico e Tecnológico. Programa Institucional de Bolsas de Iniciação Científica. Disponível em: http://cnpq.br/pibic. Acesso em: 25 de abril de 2017. 